\title{
The Process of Legal Education of Students at the University
}

\author{
Natalia P. Nikonova
}

\begin{abstract}
The modern stage of Russia's development is characterized by profound changes in all spheres of society. Along with positive changes in society, there are processes characterized by negative trends: deepening of social differentiation, changes in people's lifestyles, the destruction of the former worldview and the lack of formation of the new one, the loss of spiritual and moral values, the ongoing criminalization of society. Therefore, the problem of legal education of the younger generation has become urgent, in which the leading role is played by the activities of University teachers. The article clarifies the content of "legal education" of students at the University. The degree of elaboration of the problem of legal education of students is revealed. Pedagogical conditions promoting increase of efficiency of legal education of students of higher educational institutions are defined and experimentally checked.
\end{abstract}

Keywords: legal education, students, pedagogical conditions, pedagogical process.

\section{INTRODUCTION}

Modern life imposes new requirements on a person: the ability to make an informed choice in a situation of uncertainty, to be responsible for their actions, to adapt to social changes, to find a compromise solution, etc. But the situation in Russia is characterized by the fact that the processes of familiarization with legal norms are not supported by legal traditions, in the mass consciousness, laws are not an absolute value due to the low level of legal knowledge [3]. All this makes relevant the problem of legal education of students, in which the leading role is played by the activities of teachers of higher education.

The problem of legal education of University students occupies one of the important places in modern scientific research, which is due to changes in the cultural, historical and socio-economic situation in the country; social order for the education of law-abiding personality, able to adapt to modern socio-economic and political conditions [2].

Legal education is a complex and long process that affects the problem of socialization of personality, various aspects of which are covered in the studies Of N. F. Golovanova, I. K. Kashirskaya, A.V. Mudrik, V. S. Mukhina, N. D. Nikandrov, V. V. Pavlovsky, etc.

\section{METHODOLOGY}

The analysis of philosophical, legal, sociological, psychological and pedagogical literature shows that legal

Revised Manuscript Received on October 15, 2019.

* Correspondence Author

Natalia P. Nikonova, Tyumen Industrial University, Russia. education acts as a multi-purpose activity of teachers, students, parents, law enforcement agencies, accumulates legal experience and broadcasts legal culture $[4,9,10,11]$. Having a subjective orientation, legal education work is aimed at the development of the person himself, his legal competence. These provisions give grounds to consider legal education as a holistic pedagogical process based on specially organized, consciously carried out, systematic, interrelated activities of the subjects of education (state bodies, public organizations, teachers, students) on the translation of legal culture, legal experience, taking into account the potential capabilities of pupils, in order to form their legal competence.

The essence of this process is to translate the external, objective (legal culture, legal experience, legal ideals) into the internal, subjective personal property of pupils (legal attitudes, relations, motives of activity in the sphere regulated by law).

Considering the legal education of students as a complex pedagogical process, based on the research of leading scientists in the field (A. A. Kvasha, O. p. Nikolaev, etc.), we highlight the functions that ensure its sustainable development. The General pedagogical functions include: educational, educational, socializing, and specific-translational, integrating. The first reflect the possibilities of this process, the relationship and interdependence of its individual components, the second Express the relationship of this process to other components of the education system, their interaction.

Based on the ideas of the competence approach [1], as the goal of the process under study, we define the development of legal competence of students, which is an actual personal characteristic that provides a person with the opportunity to solve real problems in the field of relations governed by law. The cognitive component characterizes changes in the intellectual sphere of the individual, which is reflected in the degree of legal awareness, in the degree of awareness of the importance of legal knowledge. This component implements information and educational function. The motivational-value component gives the characteristic of changes in the motivational sphere of the personality. Its implementation is aimed at developing students ' value orientations, positive motivation of law-abiding activities. This component performs an orientation function. The allocation of the activity component in the structure of legal competence is due to the fact that legal competence is developed in social practice, through actions in a real situation or simulated educational situations. 
The identified components are inextricably interrelated and allow to present legal competence as a complex personal education, in which knowledge, skills, values, personal attitudes and behaviors are manifested in unity.

The content of the studied process is determined taking into account its functions, goals, objectives and can be represented by three blocks: informative-orientation block (providing students with knowledge about the meaning, main areas and mechanisms of legal regulation of public life; the rights and obligations of the state and citizens in relation to each other, the system of law; determining the optimum or sufficient minimum of legal information); motivational-stimulating block (the development of students ' interest in legal issues, the formation of positive motivation for law-abiding activities; legal attitudes and value-legal orientations; affirmation in the minds of students of views and beliefs that ensure respect for the law; education of high consciousness of students, the development of a constant need to improve the existing legal system [6]); activity-practical block (providing students with experience of law-abiding activities, the development of skills to highlight the legal aspects of emerging life situations and determine the feasibility of their resolution by legal means; the ability to see the legal consequences of decisions and actions taken; skills to use mechanisms and means of legal resolution of problems; creation of situations as close as possible to real practical activity of legal character for acquisition by students of experience of lawful and socially active behavior [8]).

Taking into account the essence of legal education, its goals, objectives and features, as well as the structure of the concept of "legal competence", the pedagogical conditions that contribute to the efficiency of the process of legal education were determined.

As the first pedagogical condition, we defined the actualization of theoretical knowledge of students through the introduction of elective legal courses. The main objectives of elective courses are: to promote the development of legal competence of students on the basis of their development of basic legal norms; to develop students ' interest in finding the necessary legal information to solve specific life situations and problems; to foster respect for law and the law [5].

The second pedagogical condition-expansion of experience of law-abiding activity. The development of the student's personality takes place in a variety of activities, so legal training should be carried out in the process of diverse types and content of students ' activities, organized by teachers using various means, methods and forms of educational work.

The third pedagogical condition is the use of pedagogical monitoring and self-monitoring to obtain objective information about the effectiveness of the process and its operational correction.

The implementation of these conditions in unity contributes to the integration of the selected components of legal competence of students.

\section{RESULTS}

The purpose of experimental research was to test the hypothesis of the study. On the basis of this goal, the following tasks were formulated: determination of the initial level of legal competence of students; implementation and verification of the effectiveness of pedagogical conditions that ensure the success of legal education of students at the University; processing of the data obtained by means of mathematical statistics and their analysis.

123 students of the branch of Tyumen Industrial University in Surgut, 12 teachers, 7 employees of internal affairs took part in various types of pedagogical experiment.

Experimental and search work was carried out in several stages: ascertaining experiment (determination of initial level of formation of legal competence of students; development of structural and functional model and pedagogical conditions); forming experiment (organization of legal education of senior teenagers on the basis of the developed model and taking into account the allocated pedagogical conditions); control experiment (final assessment of results on the allocated criteria and indicators in control and experimental groups, statement of efficiency of the allocated pedagogical conditions).

At the first stage of experimental search work with the help of a set of research methods (questionnaire, expert survey, observation, conversation, interview), the level of formation of legal competence of students was determined.

The analysis of psychological and pedagogical literature, based on the structure of the concept of "legal competence" has allowed to allocate following criteria of formation of legal competence of students: cognitive, characterizing the legal knowledge and understanding of students; activity reflecting the nature of the activities of students, having a legal focus; motivational, revealing the motives of students ' participation in law-abiding activities. Applying the level approach, we have identified four levels of formation of legal competence of students: extremely low, low, medium, high.

The results obtained during the ascertaining experiment confirmed the need to create a set of pedagogical conditions to improve the effectiveness of legal education of students.

The task of the second stage of experimental work was to implement pedagogical conditions that contribute to improving the effectiveness of legal education of students. In order to solve it, a formative experiment was conducted. In the experimental groups, changes were made to the educational process in accordance with the proposed pedagogical conditions. In the control group, the implementation of the process of legal education was carried out according to the traditional method.

The effectiveness of the experimental work was determined by quantitative and qualitative parameters, which made it possible to confirm the positive impact of pedagogical conditions on improving the effectiveness of legal education.

Comparing the results obtained in the control and experimental groups, we note that the difference in the results strongly suggests that the effectiveness of legal education of students increases with the implementation of the pedagogical conditions identified by us.

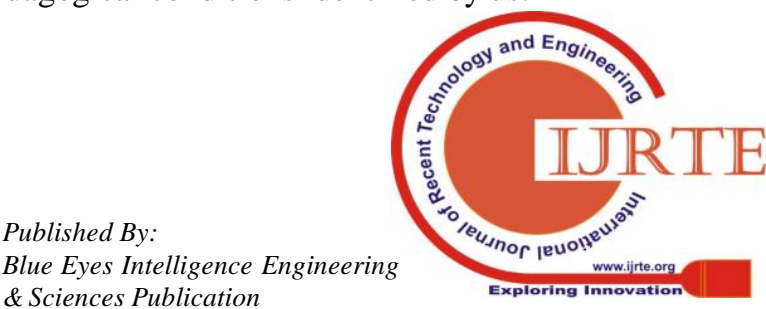




\section{CONCLUSION}

The study made it possible to draw the following conclusions. Legal education is a holistic pedagogical process based on specially organized, consciously carried out, systematic, interrelated activities of the subjects of education on the translation of legal culture, legal experience, taking into account the potential of pupils.

The peculiarities of the process of legal education students are: its focus on the formation of legal consciousness of students on the basis of assimilation by pupils of the system of legal norms and legal requirements established by the state; creation of conditions for inclusion of students in various types, forms and content of social and meaningful activities, using the possibilities leading for age activities [7]; the development of students ' readiness for constructive interaction, conflict resolution and agreement.

As the purpose of the studied process, we define the development of legal competence of students, which is an actual personal characteristic that provides a person with the opportunity to solve real problems in the field of relations governed by law. In the structure of legal competence of students there are three interrelated components: cognitive, motivational and activity.

Pedagogical conditions that ensure the effectiveness of legal education of University students include: updating theoretical knowledge through the introduction of elective legal courses; expanding the experience of law-abiding activities of students; the use of pedagogical monitoring and self-monitoring to obtain objective information about the effectiveness of the process and its operational correction.

In General, the results of experimental research confirm the assumption that the process of legal education of University students is carried out more effectively if it is implemented on the basis of a structural and functional model and taking into account the selected pedagogical conditions. The analysis of the obtained quantitative and qualitative results of experimental search work showed that the hypothesis was confirmed, the purpose of the study was achieved.

\section{REFERENCES}

[1] Andreeva E. A., Karganova A. I., Andreeva L. A. Legal education as a means of formation of legal culture and legal consciousness // Higher school. - 2016. - no. 13. - pp. 32.

[2] Denisenko I. K. Influence of institutes of legal socialization on formation of legal competence and legal behavior of the person // Historical and social-educational thought. - 2012. - no. 1 .

[3] Minina A. A. Legal education and its role in the life of modern Russian society / / international journal of experimental education. - 2011. - no. 12. pp. 92-93.

[4] Radchenko T. A. Legal socialization of personality // Bulletin of Adygea state University. Series 1: regional Studies: philosophy, history, sociology, law, political science, cultural studies. - 2010. - no. 4.

[5] Sahakyan V. M. Legal education and training as means of formation of legal culture // Vestnik of Adyghe state University. Series 1: regional Studies: philosophy, history, sociology, law, political science, cultural studies. $-2009 .-$ no. 3.

[6] Samygin P. S., Popov M. Yu., Samygin S. I. Legal socialization of youth in the conditions of crisis of modern Russian society // Bulletin Of the Russian University of peoples ' friendship. Series: Sociology. - 2016. no. 2.

[7] Suntsov E. A. Actual problems of education of legal culture of youth // Society and law. - 2009. - no. 3 (25).

[8] Gordley, J. (2000). Comparative law and legal education. Tul. L. Rev., 75, 1003.

[9] Mohr, A. J., \& Rodgers, K. J. (1973). Legal Education: Some Student Reflections. Journal of Legal Education, 25(4), 403-426.
[10] Ogden, G. L. (1984). The problem method in legal education. J. Legal Education, 34, 654.

[11] Rhode, D. L. (2000). Legal Education: Professional Interests and Public Values. Ind. L. Rev., 34, 23. 